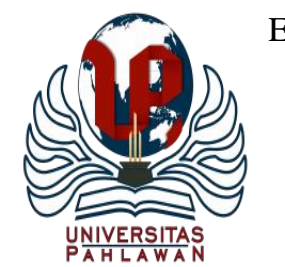

Edukatif : Jurnal Ilmu Pendidikan Volume 1 Nomor 3 Tahun 2019 Halaman 198-204

EDUKATIF: JURNAL ILMU PENDIDIKAN

Research \& Learning in Education

https://edukatif.org/index.php/edukatif/index

\title{
IMPELEMENTASI SUPERVISI DALAM MENINGKATKAN PROSES PEMBELAJARAN DAN PENDIDIKAN KARAKTER DI SEKOLAH DASAR
}

\author{
Wiwik Maladerita ${ }^{1}$, Dina Dahliana ${ }^{2}$, Maistika Ratih ${ }^{3}$, Rifma $^{4}$ \\ Universitas Negeri Padang, Sumatera Barat, Indonesia ${ }^{1,2,3,4}$ \\ e-mail : wiwikmaladerita@gmail.com ${ }^{1}$, dinadahliana23@gmail.com ${ }^{2}, \underline{\text { maistikaratihmbc@gmail.com }}^{2}$, \\ rifmar34@ fip.unp.ac.id ${ }^{3}$
}

\begin{abstract}
Abstrak
Supervisi di sekolah dilaksanakan oleh kepala sekolah yang bertindak sebagai supervisor, maka ia harus mampu melakukan berbagai pengawasan dan pengendalian untuk meningkatkan kinerja guru. Pengawasan dan pengendalian merupakan tindakan preventiv untuk mencegah agar guru tidak melakukan penyimpangan dan lebih berhati- hati dalam melaksanakan pekerjaannya sebagai pendidik. Oleh karena itu, penelitian ini mengungkap kegiatan supervisi yang dilakukan oleh Kepala sekolah SDN 14 Sungai Sirah Kecamatan Sutera Kabupaten Pesisir Selatan. Adapun hasil dari penelitian ini adalah:1). Fokus kegiatan supervisi yang dilakukan kepala sekolah dapat diidentifikasikan ke dalam dua hal yaitu; kegiatan supervisi yang menyangkut administrasi guru dan kegiatan proses belajar mengajar, 2). Kegiatan supervisi sangat membantu bagi guru dalam memecahkan masalah-masalah pendidikan yang dihadapi guru pada saat melakukanpembelajaran, serta dapat memberikan motivasi bagi guru agar selalu meningkatkan pengetahuan untuk menjadi guru yang professional dalam melaksanakan pembelajaran, 3). Hambatan kepala sekolah dalam supervisi adalah tumpang tindih kegiatan dan keterbatasan dana operasional
\end{abstract}

Kata Kunci: supervisi, pendidikan karakter

\begin{abstract}
Supervision in schools is carried out by the principal who acts as a supervisor, so he must be able to carry out various supervision and control to improve teacher performance. Supervision and control are preventive measures to prevent teachers from making deviations and to be more careful in carrying out their work as educators. Therefore, this study revealed the supervision activities carried out by the Principal of SDN 14 Sungai Sirah, Sutera Subdistrict, Pesisir Selatan District. The results of this study are: 1). The focus of supervision activities carried out by the principal can be identified in two ways, namely; supervision activities involving the administration of teachers and teaching and learning activities, 2). Supervision activities are very helpful for teachers in solving educational problems faced by teachers when doing learning, and can provide motivation for teachers to always improve their knowledge to become professional teachers in carrying out learning, 3). Barriers to school principals in supervision are overlapping activities and limited operational funds.
\end{abstract}

Keywords: supervision, character education

@Edukatif: Jurnal Ilmu Pendidikan FIP UPTT 2019

$\triangle$ Corresponding author :

Address : Kalumbuk, Padang

Email : dinadahliana23@gmail.com

ISSN 2656-8063 (Media Cetak)

Phone : 085364480340

ISSN 2656-8071 (Media Online) 
199 Implementasi Supervisi dalam Meningkatkan Proses Pembelajaran dan Pendidikan Karakter di Sekolah Dasar Wiwik Maladerita, Dina Dahliana, Maistika Ratih, Rifma

\section{PENDAHULUAN}

Guru memiliki potensi untuk berkreasi dan meningkatkan kinerjanya. Namun demikian seringkali banyak faktor yang menghambat mereka dalam mengembangkan berbagai potensinya secara optimal, baik itu berupa kemampuan guru itu sendiri dalam proses belajar mengajar, maupun sarana dan prasarana pendidikan yang tersedia. Mengingat hal tersebut sangat dirasakan perlunya supervisi yang berkesinambungan dengan program yang terarah dan sistematis terhadap guru. Program supervisi guru tersebut lazim disebut supervisi yang merupakan suatu rangkaian penting dalam manejemen pendidikan. Adapun fungsi utama dari supervisi pendidikan seperti yang dikemukakan oleh Sahertian, bahwa fungsi dasar dari supervisi adalah untuk memperbaiki situasi belajar mengajar di sekolah agar lebih baik. Supervisi terhadap proses belajar mengajar, merupakan salah satu bentuk aktivitas yang direncanakan untuk membantu para guru dalam melakukan pekerjaan mereka secara efektif (Suryani, 2015).

Dari hasil observasi awal terhadap kepala sekolah pada Sekolah Dasar SDN 15 Sungai Sirah Kecamatan Sutera Kabupaten Pesisir Selatan dalam hal supervisi pendidikan penulis menemukan bahwa pelaksanaan supervisi pendidikan oleh kepala sekolah belum memberikan kontribusi yang positif terhadap peningkatan guru dalam proses belajar mengajar. Kenyataannya masih ada sebahagian guru yang mengajar lepas, dalam arti tidak menggunakan acuan yang telah ditetapkan untuk diemban oleh seorang guru, seperti: Guru mengajar tidak menggunakan
Silabus, Kurikulum, Program Tahunan (PROTA), Program Semester (PROSEM), dan Rancangan Program Pembelajaran (RPP) serta kurangnya disiplin dan tanggung jawab terhadap tugas yang sedang dilakukan. Teknik supervisi yang dilakukan oleh kepala sekolah belum mempengaruhi terhadap peningkatan proses belajar mengajar guru di MIN Sukadamai Kota Banda Aceh.

\section{METODE}

Penelitian ini adalah penelitian kepustakaan atau library research. Penelitian ini bertujuan untuk mengkaji teks, buku-buku dan naskah publikasi mengenai supervisi dan pendidikan karakter. Adapun kajian ini diambil dari naskah-naskah kepustakaan yang relevan dengan topik penelitian yaitu berkaitan dengan topik yang dibahas (Yayuk Cicilia, 2019).

Sumber data yang digunakan adalah data-data hasil penelitian terdahulu yang relevan. Langkah-langkah yang dilakukan dalam penelitian ini diantaranya adalah pengumpulan data pustaka, membaca, mencatat, serta membandingkan literatur untuk kemudian diolah dan menghasilkan kesimpulan. Data yang digunakan merupakan data skunder berasal dari teksbook, jurnal, article ilmiah dan literature review yang berisikan tentang konsep yang sedang dikaji.

\section{HASIL DAN PEMBAHASAN}

Pengertian Supervisi Pendidikan Kata supervisi berasal dari bahasa Inggris yaitu supervision, terdiri atas dua kata, yaitu super dan vision yang mengandung pengertian melihat dengan sangat teliti 
pekerjaan secara keseluruhan. Orang yang melakukan supervisi yang disebut supervisor.

Tim Direktorat Jenderal Kelembagaan Agama Islam (2003:31).

Pengertian supervisi dalam kaitannya dengan pendidikan adalah pembinaanguru. Konsep supervisi tradisional menganggap supervisi sebagai inspeksi. Hal inilah yang menyebabkan guru merasa takut dan tidak bebas melakukan tugasnya serta merasa terancam dan merasa takut untuk bertemu dengan supervisor, bahkan supervisor dianggap tidak memberikan dorongan bagi kemajuan guru. Sikap tersebut dipengaruhi oleh pemahaman tentang supervisi secara tradisional, artinya supervisor dipahami sebagai pengawasan dalam pengertian mencari-cari kesalahan dan menemukan kesalahan untuk diperbaiki yang pada gilirannya mempengaruhi penilaian terhadap guru. Sahertian (2006:16)

Dalam pengertian lain, supervisi merupakan peningkatan makna dari inspeksi yang berkonotasi mencari-cari kesalahan, jelaslah bahwa kesan seperti itu sangat kurang tepat dan tidak sesuai lagi dengan zaman reformasi seperti sekarang ini.

Kegiatan supervisi mencakup penentuan kondisi-kondisi atau syarat-syarat personil maupun material yang diperlukan untuk terciptanya situasi belajar mengajar yang efektif, dan usaha memenuhi syarat-syarat itu (Elvi Selva Nirwana, 2013).

Tujuan dan Fungsi Supervisi Pendidikan Supervisi adalah proses bantuan bagi guru untuk mengembangkan kemampuannya yang meliputi pengetahuan, keterampilan mengajar dan komitmen atau motivasi guru. Jadi tujuan supervisi berkaitan dengan aspek kognitif, psikomotor dan afektif adalah membantu memperbaiki dan meningkatkan pengelolaan sekolah sehingga tercapai kondisi kegiatan belajar mengajar yang sebaik-baiknya. (Suryani, 2015)

Adapun fungsi pokok supervisi pendidikan ditujukan pada perbaikan dan peningkatan proses belajar mengajar guru di sekolah. Sehubungan dengan hal ini, menurut pendapat Malik supervisi terhadap kinerja guru dalam proses belajar mengajar memiliki tiga fungsi utama yaitu:

a. Supervisi kurikulum untuk menjamin penyampaian kurikulum dengan tepat.

b. Perbaikan proses pembelajaran dengan membantu guru merencanakan program akademis.

c. PengembanganProfesi dalammelaksanakan program pengajaran(Dewi, 2019)

Fungsi pengawasan ini sangat penting dan sangat menentukan pelaksanaan proses manajemen, peranan pengawasan juga sangat menentukan baik atau buruknya suatu rencana, oleh karena itu harus dilakukan dengan sebaik baiknya. Pengawasan diartikan sebagai proses mengukur serta menilai tingkat efektivitas kinerja organisasi serta tingkat efisiensi penggunaan sarana kerja pada pencapaian tujuan organisasi (Amtu dalam Atik Maisaro, Bambang Budi Wiyono, 2018).

Soetjipto dan Raflis Kosasi dalam bukunya Profesi Keguruan mengatakan, bahwa tugas supervisor itu meliputi: 
201 Implementasi Supervisi dalam Meningkatkan Proses Pembelajaran dan Pendidikan Karakter di Sekolah Dasar Wiwik Maladerita, Dina Dahliana, Maistika Ratih, Rifma

1. Tugas perencanaan, yaitu untuk menetapkan Kebijaksanaan dan program.

2. Tugas Administrasi, yaitu pengambilan keputusan serta pengkoordinasian melalui konferensi dan konsultasi yang dilakukan dalam usaha perbaikan kualitas pengajaran.

3. Partisipasi secara langsung dalam pengembangan kurikulum, yaitu dalam kegiatan merumuskan tujuan membuat penuntun mengajar bagi guru, dan memilih isi pengalaman belajar.

4. Melaksanakan demontrasi mengajar untuk guru-guru Melaksanakan penelitian.

Karakter secara harafiah berarti "kualitas mental atau moral, kekuatan moral, nama atau reputasi. karakter adalah kualitas atau kekuatan mental atau moral, akhlak atau budi pekerti individu yang merupakan kepribadian khusus yang menjadi pendorong atau penggerak, serta yang membedakan dengan individu lain. Seseorang dapat dikatakan berkarakter ketika orang tersebut telah berhasil menyerap nilai dan keyakinan yang dikehendaki masyarakat serta digunakan sebagai kekuatan moral dalam hidupnya (Sormin \& Rahma Rangkuti, 2018).

Karakter adalah suatu system penanaman nilai-nilai karakter kepada warga sekolah yang meliputi komponen pengetahuan, kesadaran atau kemauan, dan tindakan untuk melaksanakan nilai-nilai tersebut, baik terhadap Tuhan YME, diri sendiri, sesama, lingkungan, maupun kebangsaan sehingga menjadi manusia (Marlini \& Zaki Al Fuad, 2018).
Pendidikan karakter merupakan pendidikan penanaman nilaidan norma kepada warga sekolah untuk menumbuhkan kesadaran dalam menjalankan kewajiban kepada Tuhan YME, serta berbuat baik kepada diri sendiri, lingkungan dan sesama manusia untuk menghasilkan manusia yang berbudi luhur (Putri, Voni Elsa, Rifma, Irsyad, 2019). Menurut (Kebudayaan 2017) ada lima nilai utama karakter yang perlu dikembangkan di sekolah sebagai prioritas.

Pendidikan karakter merupakan sistem penanaman nilai-nilai karakter kepada peserta didik. Nilai-nilai yang ditanamkan itu berkaitan dengan upaya meningkatkan kecerdasan, memperkuat jiwa/batin, membina rasa/hubungan kemanusiaan, dan membentuk sportifitas dan kesehatan fisik. Semua nilainilai itu ditanamkan agar generasi Indonesia tumbuh menjadi pribadi yang kuat dan memiliki jati diri yang mencerminkan karakter bangsa Indonesia (Muzzamil, 2019).

Gerakan PPK, diantaranya yaitu: Pertama Religius, nilai religius merupakan nilai yang mencerminkan adanya kepercayaan dan keyakinan terhadap Tuhan yang Maha Esa.Yang mana hal tersebut di wujudkan dengan melaksanakan segala perintah-Nya dan menjauhi segala larangan-Nya. Namun tidak hanya itu, nilai religius mencerminkan sikaptoleransi yang tinggi antara umat beragama, kerjasama serta menciptakan hubungan yang harmonis antar sesame makhluk tuhan. Nilai-nilai yang terkandung dari karakter religius ini diantaranya yaitu: percaya diri, kerja sama antar pemeluk agama, mencintai lingkungan, dan lain sebagainya. 
202 Implementasi Supervisi dalam Meningkatkan Proses Pembelajaran dan Pendidikan Karakter di Sekolah Dasar Wiwik Maladerita, Dina Dahliana, Maistika Ratih, Rifma

Kedua Nasionalis, nilai karakter nasionalis merupakan cerminan sikap yang menunjukkan kesetiaan, kepedulian, serta penghargaan yang tinggi terhadap kepentingan bangsa dan negaradi atas kepentingan diri sendiri dan anggota kelompoknya. Nilai-nilai yang terkandung dari karakter nasionalis sendiri yaitu: apresiasi terhadap budaya sendiri, menjaga kekayaan bangsa,rela berkorban, cinta tanah air, menjaga lingkungan,taat hukum, disiplin, menghormati keragaman budaya, suku, dan agama.

Ketiga Mandiri, nilai karakter mandiri merupakan perilaku yang tidak mau bergantung pada orang lain. Nilai-nilai yang terkandung dari nilai karakter mandiri ini antara lain: kerja keras, tahan banting, profesional, kreatif, dan keberanian.

Keempat Gotong Royong, nilai karakter gotong royong merupkan sikap mau melakukan kerjasama dengan orang lain untuk mencapai suatu tujuan bersama, menjalin komunikasi yang baik serta mampu untuk saling bahu membahu dalam melaksanakan sesuatu hal kebaikan. Subnilai gotong royong antara lain menghargai, kerja sama, komitmen atas keputusan bersama, musyawarah mufakat, solidaritas, empati, anti kekerasan, dan memilikirasa kerelawanan yang tinggi..

Kelima Integritas, nilai karakter integritas merupakan nilai yang menjadikan diri seseorangdapat di percaya, baik di lingkungan keluarga, sekolah maupun masyarakat. Nilai-nilai yang terkandung dari karakter integritas antara lain kejujuran, cinta pada kebenaran, setia, komitmen moral, anti korupsi, keadilan, tanggungjawab, keteladanan, dan menghargai martabat seorang individu.

Beberapa fakta rendahnya karakter suatu bangsa tercermin pada peserta didik, diantaranya adalah rendahnya kejujuran siswa yang dibuktikan dengan adanya budaya cheating pada saat ujian, rendahnya adab atau etika dalam bersikap dan rasa hormat kepada orang tua dan guru, kurangnya etika dalam menggunakan bahasa yang sopan dan santun dan tingginya kasus perkelahian dan kriminal yang dilakukan peserta didik pada tingkat satuan pendidikan dasar dan menengah. Beberapa fenomena tersebut sesuai dengan hasil penelitian yang dilakukan oleh Asep Saipul Hidayat di Dinas Pendidikan Kabupaten Garut pada tahun 2012 (Hidayat dalam Mukhlisoh, Mujahidatun, 2019).

Pendidikan karakter memiliki tiga fungsi utama. Pertama, fungsi pembentukan dan pengembangan potensi. Pendidikan karakter membentuk dan mengembangkan potensi siswa agar berpikiran baik, berhati baik, dan berperilaku sesuai dengan falsafah pancasila. Kedua, fungsi perbaikan dan penguatan. Pendidikan karakter memperbaiki dan memperkuat peran keluarga, satuan pendidikan, masyarakat, dan pemerintah untuk ikut berpartisipasi dan bertanggung jawab dalam pengembangan potensi warga negara dan pembangunan bangsa menuju bangsa yang maju, mandiri, dan sejahtera. Ketiga, fungsi penyaring. Pendidikan karakter memilah budaya bangsa sendiri dan menyaring budaya bangsa lain yang tidak sesuai dengan nilainilai budaya bangsa dan karakter bangsa yang bermartabat (Zubaidi dalam Wulandari \& Kristiawan, 2017). 
203 Implementasi Supervisi dalam Meningkatkan Proses Pembelajaran dan Pendidikan Karakter di Sekolah Dasar Wiwik Maladerita, Dina Dahliana, Maistika Ratih, Rifma

Pelaksanaan kegiatan penguatan pendidikan karakter juga dilakukan pengawasan, monitoring dan evaluasi secara berkala, baik harian, mingguan, bulanan, triwulan, semester dan tahunan. Pengawasan pelaksanaan penguatan pendidikan karakter ini dilakukan oleh guru, kepala sekolah, komite sekolah dan pengawas. Pengawasan yang dilakukan bertujuan untuk mencari tahu tentang kelemahan dan kekuatan yang terjadi selama pelaksanaan program penguatan pendidikan karakter, baik dari aspek materi maupun kinerja pada siswa dan juga guru yang melaksanakan pendidikan karakter siswa (Rohman, 2017).

Faktor-faktor pendukung dalam implementasi pendidikan karakter dalam pembelajaran diantaranya siswa yang aktif dalam setiap pembelajaran yang dilaksanakan di kelas maupun di luar kelas. Pembelajaran yang baik adalah pembelajaran yang menuntut keaktifan siswa. Melalui proses pembelajaran dengan keterlibatan aktif siswa iniberimplikasi terhadap siswa itu sendiri untuk membangun pengetahuannya sehingga mereka akan memperoleh pemahaman yang mendalam dan akhirnya meningkatkan kompetensi siswa tersebut (Wiliandani, Wiyono, \& Sobri, 2016).

\section{SIMPULAN}

Pengawasan merupakan salah satu
upaya untuk meningkatkan dan
meningkatkankompetensi guru dalam
pembelajaran. Pengawasan di tingkat satuan
pendidikandilakukan oleh kepala sekolah dan
pengawas. Hasil penelitian menunjukkan
bahwakepala sekolah telah melakukan pengawasan terhadap guru. Mereka melakukan sesuaidengan pemahaman mereka dengan arti pengawasan. Kepala sekolah dan gurumenafsirkan pengawasan sebagai suatu kegiatan penilaian, sehingga kepala sekolahdan guru berharap pengawasan yang akan dilakukan untuk guru dalam kondisi siapuntuk dinilai.

Metode dan hasil yang disajikan dalam artikel ini dapat bermanfaat bagikepala sekolah dan guru dalam meningkatkan layanan pengawasan untukmencapai perbaikan dan meningkatkan kompetensi guru dalam melaksanakantugas mengajar.

Saran yang disampaikan dari penelitianini agar guru lebih meningkatkan kompetensinya melalui berbagai solusi yang telahpeneliti paparkan, agar pendidikan di sekolahdapat mencapai tujuan pendidikan menurutUndang-Undang 1945.

\section{DAFTAR PUSTAKA}

Atik Maisaro, Bambang Budi Wiyono, I. A. (2018). Manajement Program Penguatan Pendidikan Karakter di Sekolah Dasar. Jurnal Adminitrasi Dan Manajemen Pendidikan, 1(3), 302-312.

Dewi, F. (2019). Prosiding seminar nasional pendidikan program pascasarjana universitas pgri palembang 03 mei 2019, 239-250.

Elvi Selva Nirwana. (2013). REVITALISASI PERAN DAN TUGAS PENGAWAS DALAM SUPERVISI PEMBELAJARAN UNTUK MENGAWAL KURIKULUM 2013. AtTa'lim, 2(12), 339-351.

Marlini, C., \& Zaki Al Fuad, H. (2018). Kajian implementasi penanaman karakter dalam kurikulum 2013 di kelas iv sdn 19 kota banda aceh. Seminar Nasional Pendidikan Dasar, 588-595. 
Mukhlisoh, Mujahidatun, S. (2019). IMPLEMENTASI MANAJEMEN PENDIDIKAN KARAKTER DI SEKOLAH. Jurnal Darussalam; Jurnal Pendidikan, Komunikasi Dan Pemikiran Hukum Islam, XI(1), 56-75.

Muzzamil. (2019). PELAKSANAAN PENDIDIKAN KARAKTER BANGSA DI SEKOLAH BINAAN. Journal of Civic Education, 2(2), 29-37.

Putri, Voni Elsa, Rifma, Irsyad, A. (2019). ANALISIS KOMPETENSI PEDAGOGIK GURU DALAM PENGIMPLEMENTASIAN PENDIDIKAN KARAKTER DI SD NEGERI KECAMATAN KOTO TANGAH. Jurnal Bahana Manajemen Pendidikan, 8(3), 1-6. https://doi.org/10.1017/CBO9781107415 324.004

Rohman, N. (2017). Di Sekolah Dasar ( Studi Di Sd Ut Bumi Kartini, (0291), 146-154.

Sahertian. 2000. Konsep Dasar dan Teknik Supervisi Pendidikan Dalam Rangka PengembanganSumber Daya Manusia, Jakarta: Rineka Cipta.

Sormin, D., \& Rahma Rangkuti, F. (2018). Strategi Guru Dalam Membentuk Karakter Siswa Mi Terpadu Mutiara Kota Padangsidimpuan. TAZKIR: Jurnal Penelitian Ilmu-Ilmu Sosial Dan Keislaman, $\quad 4(2), \quad 219$. https://doi.org/10.24952/tazkir.v4i2.1107

Suryani, C. (2015). DALAM MENINGKATKAN PROSES BANDA ACEH, 16(1), 23-42.

Tim Direktorat Jenderal Kelembagaan Agama Islam. 2003. Pedoman Pengembangan Administrasi dan Supervisi Pendidikan, Jakarta: Departemen Agama RI,.

Wiliandani, A. M., Wiyono, B. B., \& Sobri, A. Y. (2016). Implementasi Pendidikan Karakter dalam Pembelajaran di Sekolah Dasar. Jurnal Pendidikan Humaniora (JPH), 4(3), 132-142. https://doi.org/10.17977/JPH.V4I3.8214
Wulandari, Y., \& Kristiawan, M. (2017). Strategi Sekolah Dalam Penguatan Pendidikan Karakter Bagi Siswa Dengan Memaksimalkan Peran Orang Tua. JMKSP (Jurnal Manajemen, Kepemimpinan, Dan Supervisi Pendidikan), 2(2), 290-302.

Yayuk Cicilia, N. (2019). Gaya dan Strategi belajar Bahasa. Jurnal Ilmu Pendidikan, 1(1), 138-149. Retrieved from https://edukatif.org/index.php/edukatif/in dex 